\title{
NUMERICAL STUDY ON EFFECTS OF TENON SIZES ON WITHDRAWAL LOAD CAPACITY OF MORTISE AND TENON JOINT
}

\author{
TianXing ZHANG \\ WuYi University \\ China \\ Wengang Hu \\ Nanjing Forestry University \\ China \\ (Received June 2020)
}

\begin{abstract}
The effect of tenon length and tenon width on withdrawal load capacity of mortise and tenon (M-T) joint was studied based on the finite element method (FEM), and the relationship of withdrawal load capacity relating to tenon length and tenon width was regressed using response surface method. The results showed that the tenon length and tenon width had remarkable effects on withdrawal load capacity of M-T joint T-shaped sample. The effect of tenon length on withdrawal load capacity was greater than tenon width. The regression equation used to predict the withdrawal load capacity was capable of optimizing the tenon sizes of M-T joint with R-square of 0.926 . Using FEM can get more knowledge of M-T joint visually, and reduce the costs of materials and time of experiments.
\end{abstract}

KEYWORDS: Withdrawal load capacity, finite element method, tenon size effect, mortise and tenon joint.

\section{INTRODUCTION}

Mortise and tenon (M-T) is a traditional joint type commonly used in wood structures and wood products, which dominates the strength of the whole framework. Withdrawal load capacity is a common load type imposed on M-T joint. Many studies have investigated the factors influencing the withdrawal resistance of M-T joint, such as wood species, adhesive type, tenon geometry etc. (Záborský et al. 2017, Zhao et al. 2019). Diler et al. (2017) studied the withdrawal resistance of T-shaped joint made from heat-treated pine (Pinus sibirica) and common ash (Fraxinus excelsior) and iroko (Chlorophora excelsa) wood. The results showed 
that the withdrawal resistances of joints constructed from common ash and iroko wood were higher than the joint made from heat-treated wood. Heat-treated wood reduced the withdrawal resistance of joint by $25 \%$. Renbutsu and Koizumi (2018) used greenwood shrinkage as a clamping pressure to increase the withdrawal resistance. The results showed that proposed shrink-fitted glued round M-T joint exhibited sufficient withdrawal strength, and after applying four humidity cycles to simulate seasonal variations in moisture content, withdrawal strength did not decrease significantly. In addition, Eckelman et al. (2004) studied the withdrawal resistance of pined and unpinned round M-T joint. The results showed that cross-pined round M-T joints enhanced the withdrawal resistance, which would be usable in the construction of furniture where adhesives were unobtainable. Derikvand et al. (2013) studied the effect of wood species and loose tenon length on the withdrawal force capacity of M-T joint T-shaped sample. The results showed that the gluing in length of the tenon exerted a significant influence on the withdrawal force capacity of the joints. Tenon sizes, length and width, are basic parameters of M-T joint, which affect the strength of M-T joint directly. A huge amount of experimental tests were conducted to investigate the tenon sizes on bending moment strength of M-T joint (Wilczyński and Warmbier 2003, Edirl et al. 2005, Likos et al. 2012, Oktaee et al. 2014, Kasal et al. 2016), and tenon shoulder on strength of M-T joint (Eckelman and Haviarova 2006, Džinčić 2016). However, the effect of tenon sizes on withdrawal load capacity of M-T joint was rarely studied.

Finite element method (FEM) has been confirmed as an effective method commonly used in wood engineering (Zhou et al. 2017, Liu et al. 2018, Hu et al. 2019, Xi et al. 2020). Previous studies also proved that the FEM can be used to analyse the M-T joint (Smardzewski 2008, Silvana and Smardzewski 2010, Çolakoglu and Apay 2012, Zhou 2018, Kilic et al. 2018, Chen 2019). Therefore, in this study, the effect of tenon sizes (length and width) on withdrawal load capacity of M-T joint was investigated numerically based on FEM, and the relationship of withdrawal load capacity relating to tenon length and tenon width was regressed using response surface method. This study will contribute to reduce the costs of experiments through using FEM and response surface method.

\section{MATERIAL AND METHODS}

\section{Material properties of wood}

The wood used to prepare the T-shaped specimens was beech (Fagus orientalis Lipsky) (Nanjing Wood Lumber, Nanjing, China). The physical and mechanical properties of beech wood were measured in the author' previous study (Hu and Guan 2017a). The specific gravity of beech averaged 0.69 , and the moisture content was $10.8 \%$. Tab. 1 shows the mechanical properties of beech wood which are basic parameters used in the finite element model, including elastic moduli, Poisson's ratios, shear moduli, yield strengths and ultimate strengths.

Tab. 1: Mechanical properties of beech wood (Hu and Guan 2017a).

\begin{tabular}{|c|c|c|c|c|c|c|c|c|}
\hline \multicolumn{3}{|c|}{ Modulus of elasticity (MPa) } & \multicolumn{6}{|c|}{ Poisson's ratio } \\
\hline $\mathrm{E}_{\mathrm{L}}^{*}$ & $\mathrm{E}_{\mathrm{R}}$ & $\mathrm{E}_{\mathrm{T}}$ & $v_{L R}$ & $v_{\mathrm{LT}}$ & $v_{\mathrm{RT}}$ & $v_{\mathrm{TR}}$ & $v_{\mathrm{TL}}$ & $v_{\mathrm{RL}}$ \\
\hline 12205 & 1858 & 774 & 0.502 & 0.705 & 0.526 & 0.373 & 0.038 & 0.078 \\
\hline \multicolumn{3}{|c|}{ Shear modulus (MPa) } & \multicolumn{3}{|c|}{ Yield strength (MPa) } & \multicolumn{3}{|c|}{ Ultimate strength (MPa) } \\
\hline $\mathrm{G}_{\mathrm{LR}}$ & $\mathrm{G}_{\mathrm{LT}}$ & $\mathrm{G}_{\mathrm{RT}}$ & $\mathrm{L}$ & $\mathrm{R}$ & $\mathrm{T}$ & $\mathrm{L}$ & $\mathrm{R}$ & $\mathrm{T}$ \\
\hline 899 & 595 & 195 & 53.62 & 12 & 6.23 & 59.20 & 48.88 & 23.82 \\
\hline
\end{tabular}

Note:" $\mathrm{E}$ is elastic modulus (MPa); $v$ is Poisson's ratio; $G$ is shear modulus (MPa); L, R, and T refer to the longitudinal, radial, and tangential directions of beech wood, respectively. 


\section{Dimensions of $\mathrm{M}-\mathrm{T}$ joint specimens}

Fig. 1 shows the configurations of T-shaped specimen evaluated in this study. The dimensions of the post leg were $200 \times 40 \times 40 \mathrm{~mm}$ (length $\times$ width $\times$ thickness). The stretcher measured $160 \mathrm{~mm}$ long $\times 30 \mathrm{~mm}$ wide $\times 30 \mathrm{~mm}$ thick. The dimensions of tenon length and tenon width were variables studied in this study, while the tenon thickness was a constant. The fit between tenon width and mortise height was 0.2 interference fit, and $0.2 \mathrm{~mm}$ clearance fit was applied between tenon thickness and mortise width according to common wood M-T joint technique. The polyvinyl acetate (PVA) was used to connect mortise and tenon, and the bonding strengths of M-T joint were shown in Tab. 2.

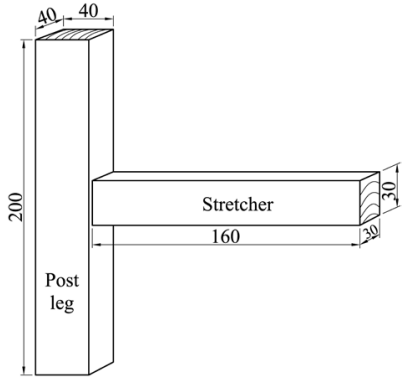

(a)

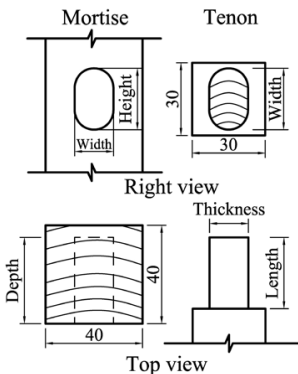

(b)

Fig. 1: Dimensions of specimen: (a) T-shaped sample, (b) mortise and tenon joint (unit mm).

Tab. 2: Bonding strength of mortise and tenon joint (Hu and Guan 2019).

\begin{tabular}{ccc}
\hline Shear strength $\mathrm{G}_{\mathrm{I}}$ & $\begin{array}{c}\text { Bonding strength (MPa) } \\
\text { Shear strength } \mathrm{G}_{\mathrm{II}}\end{array}$ & Internal bonding strength \\
\hline 3.49 & 2.45 & 1.23 \\
\hline
\end{tabular}

\section{Finite element model}

Fig. 2 shows the finite element model of the M-T joint T-shaped sample subjected to withdrawal load established using finite element software (ABAQUS 6.14-1, Dassult, Providence, RI, USA). The mode considered the orthotropic properties of wood. The mechanical properties used in this model were shown in Tab. 1. In this study, ductile damage was used in the finite element model to judge the failure of elements with the parameters of fracture strain 0.00833 , stress triaxiality 0.33 , strain rate 0.01 and displacement at failure $0.6452 \mathrm{~mm}$. Local coordinates were used to define the grain orientations of the leg and the stretcher, i.e., $\mathrm{x}, \mathrm{y}$, and $\mathrm{z}$ corresponded to the longitudinal, radial, and tangential directions, respectively. The oval M-T joint model was regarded as a semi-rigid joint. The interactions of the mortise and tenon were surface-to-surface contact. For the curve contact surfaces of the M-T joint, the penalty friction formulation was specified with a friction coefficient of 0.54 ( $\mathrm{Hu}$ and Guan 2017b) to simulate the friction behaviour between the mortise and tenon with a $0.2 \mathrm{~mm}$ interference fit. For the flat contact surfaces of the M-T joint, Traction-Separation law was used as criterion to simulate the cohesive bonding behaviour, and the parameters needed in ABAQUS were bonding strengths of glue joint in different directions shown in Tab. 2. The loading conditions was that a displacement load applied at the loading point at the end of the stretcher to get the force $(F)$ shown in Fig. 2. The mesh of the model is also shown in Fig. 2, and the sizes of most elements 
were approximately $5 \mathrm{~mm}$. For contact parts, the sizes of elements were about $2 \mathrm{~mm}$. The element type was $\mathrm{C} 3 \mathrm{D} 8$, an 8-node linear brick element that was assigned to the T-shaped sample.

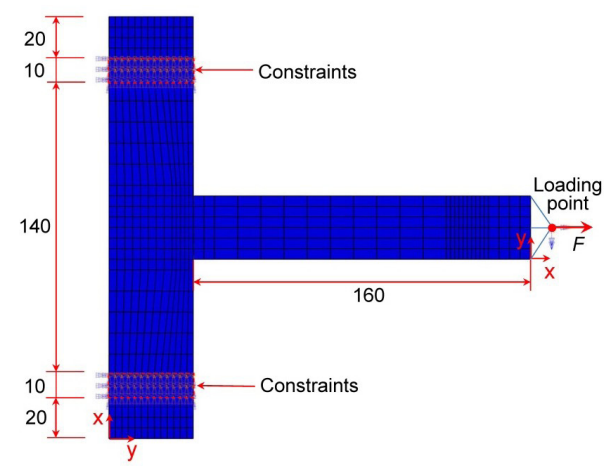

Fig. 2: Finite element models of T-shaped mortise and tenon joint subjected to withdrawal load.

Tab. 3: Combinations of tenon width and tenon length evaluated in this study.

\begin{tabular}{lccc}
\hline Tenon size $(\mathbf{m m})$ & & Width $(\mathbf{W})$ & \\
Length $(\mathbf{L})$ & $\mathbf{1 5}$ & $\mathbf{2 0}$ & $\mathbf{2 5}$ \\
\hline 10 & L10-W15 & L10-W20 & L10-W25 \\
20 & L20-W15 & L20-W20 & L20-W25 \\
30 & L30-W15 & L30-W20 & L30-W25 \\
40 & L40-W15 & L40-W20 & L40-W25 \\
\hline
\end{tabular}

\section{Statistical analysis}

All data were analyzed by Design expert (Version 8.06, Stat-Ease, Inc. Minneapolis, MN, USA) using the response surface method, and the model terms were statistically analyzed by analysis of variance (ANOVA).

\section{RESULTS AND DISCUSSION}

\section{Stress distributions of M-T joint}

Fig. 3 shows stress distributions of a typical T-shaped M-T joint (L10-W15) during withdrawal process. Most simulation results were in the same trend. Figs. 3a-d suggested the initial state, interference fit, half-tenon withdrawal and complete withdrawal states, respectively.

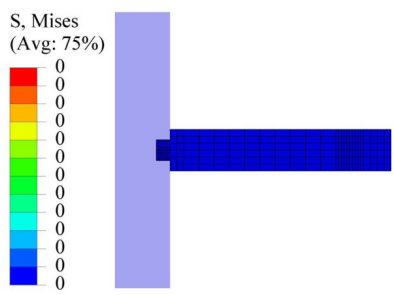

(a)

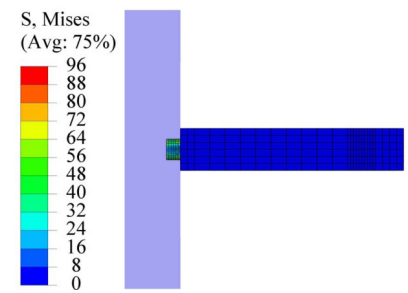

(b) 


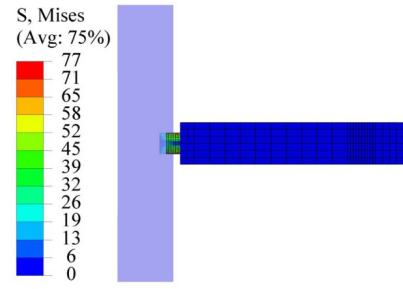

(c)

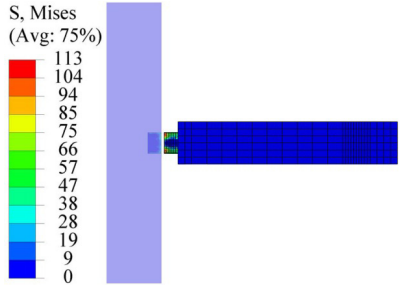

(d)

Fig. 3: Stress distributions of M-T joint T-shaped specimen subjected to withdrawal load: (a) initial state, (b) interference fit state, (c) half-tenon withdrawal state and (d) complete withdrawal state.

\section{Withdrawal load capacity of M-T joints}

Fig. 4 shows the withdrawal load and displacement curves of all M-T joint T-shaped finite element models. Most curves were in the same trend that the withdrawal load increased linearly until reaching the peak value, and then dropped linearly until the tenon completely pulled out. These curves reflected the process of tenon pulled out the mortise smoothly and the most materials of tenon were in elastic stage. However, the curves of L30-W15, L40-W15 and L40-W20 had different trends at the dropped stage of curves, which caused by different failure modes of M-T joint.

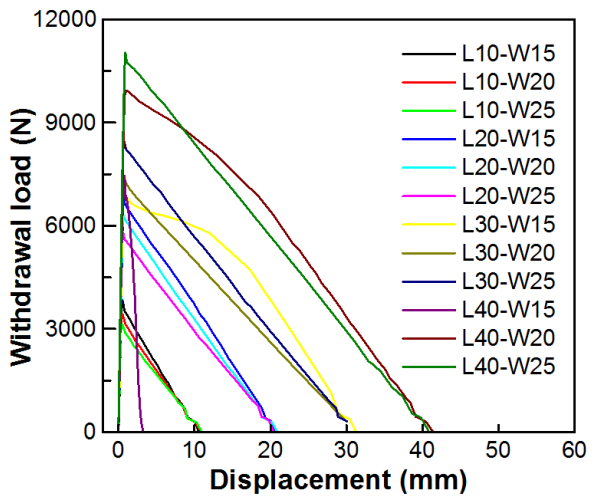

Fig. 4: Withdrawal load-displacement curves of T-shaped specimens with different tenon sizes.

Fig. 5a-c show the failure modes of M-T joint with the tenon sizes of L30-W15, L40-W15 and L40-W20, respectively. In case of Fig. 5b, the tenon damaged before pulled out, so the withdrawal load decreased once reaching the peak value. In case of Fig. $5 \mathrm{a}$ and $5 \mathrm{c}$, in the dropped stage of curves, the withdrawal load decreased nonlinearly, since most materials of tenon were in plastic stage, especially for M-T joint with tenon sizes of L30-W15. It can be inferred that when the tenon length is twice bigger than or equal to tenon width, the materials of tenon have the risk of suffering plasticity or fracture. Therefore, it is recommended that the tenon length is greater than tenon width and smaller than twice tenon width in designing the tenon sizes of M-T joint of wood products especially subjected to withdrawal load. 


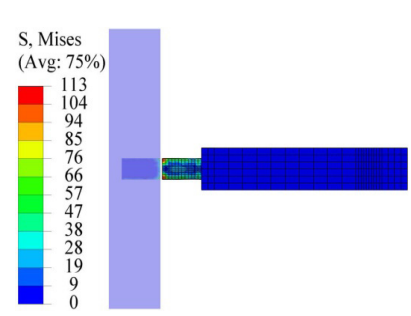

(a)

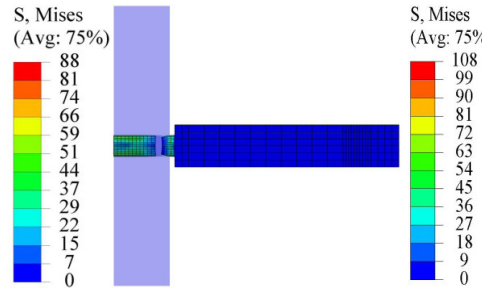

(b)

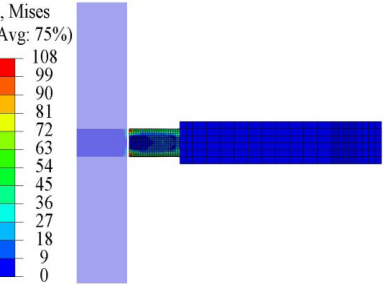

(c)

Fig. 5: Stress distributions and failure modes of T-shaped specimens subjected to withdrawal load: (a) 30-mm tenon length by 15-mm tenon width (L30-W15), (b) 40-mm tenon length by 15-mm tenon width (L40-W15) and (c) 40-mm tenon length by 20-mm tenon width (unit MPa).

Fig. 6 shows the simulation results of withdrawal load capacities of M-T joint with different tenon sizes. Apart from the tenon sizes of L40-W15, when the tenon width is fixed at a certain value, the withdrawal load capacities increased remarkably with increase of tenon length (Derikvand et al. 2013). However, when the tenon length kept at a certain constant, the withdrawal load increased or decreased slightly with the tenon width increasing. All of above results indicated that the tenon length affected the withdrawal load capacity greater than tenon width.

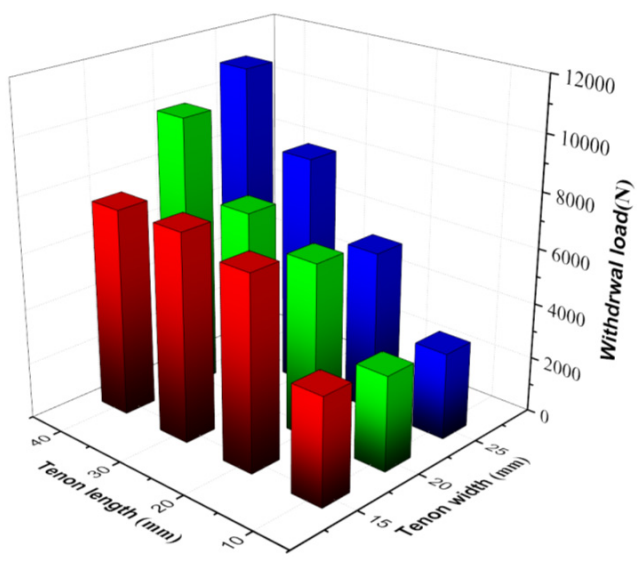

Fig. 6: Withdrawal load capacities of mortise and tenon joint with different tenon sizes.

\section{Modelling of withdrawal load capacity}

In this model, the result of M-T joint with dimensions of L40-W15 was eliminated from the data for its failure mode (Fig. 5b) different from others. Therefore, the response surface model was regressed based on 11 runs. Fig. 7 shows the 3D surface of the model, and the corresponding response surface model equation was shown in Eq. 1:

$F=4720.9+834.5 \times A-650.8 \times B+8.8 \times A B-34.2 \times A^{2}+11.1 \times B^{2}+0.44 \times A^{3}$

where: $F$ is withdrawal load capacity $(\mathrm{N})$;

$A$ and $B$ are tenon length and tenon width (mm), respectively. 


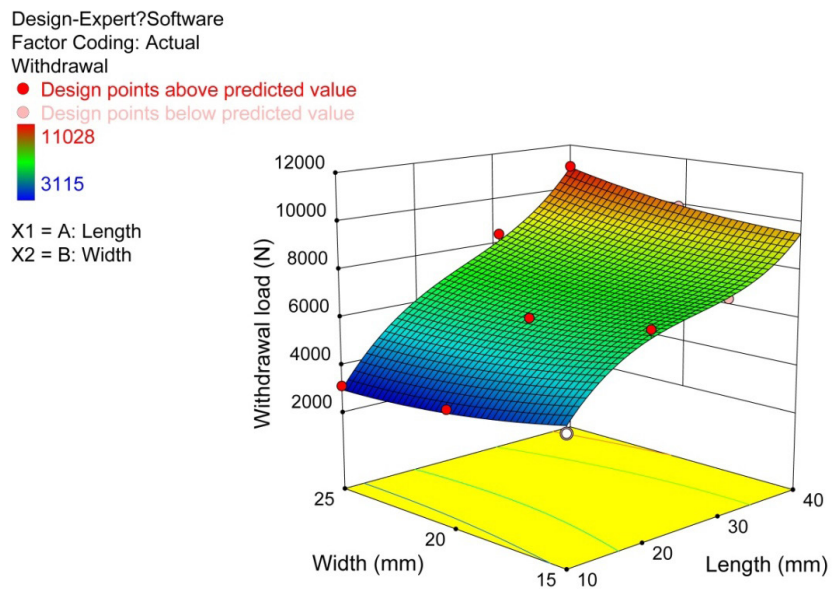

Fig. 7: 3D surface of response surface model of withdrawal capacity of mortise and tenon joint relating to tenon length and tenon width.

Tab. 4 shows that analysis of variation (ANOVA) of the response surface reduced cubic model. The $F$-value of 61.29 implies the model is significant. There is only a $0.07 \%$ chance that a $F$-Value this large could occur due to noise. The $F$-value of length was much bigger than the one of width indicating that the effect of tenon length on withdrawal load capacity was greater than tenon width, which was consistent with the results of simulation (Fig. 6).

Tab. 4: ANOVA of response surface reduced cubic model.

\begin{tabular}{ccc}
\hline Source & F-value & p-value \\
\hline Model & 61.29 & 0.0007 \\
Length (A) & 10.33 & 0.0325 \\
Width (B) & 0.15 & 0.7165 \\
AB & 6.03 & 0.0700 \\
A2 & 0.80 & 0.4219 \\
B2 & 1.01 & 0.3720 \\
A3 & 5.56 & 0.0779 \\
\hline
\end{tabular}

The $p$-values less than 0.05 indicate model terms are significant. The $p$-values greater than 0.1 indicate the model terms are not significant. The $p$-values between 0.05 and 0.1 are moderately significant Therefore, $A$ is significant model terms, $A B$ and $A^{3}$ are moderately significant, and $B, A^{2}$ and $B^{2}$ are not significant. In addition, the "Pred R-Squared" of 0.9261 is in reasonable agreement with the "Adj R-Squared" of 0.9731 . Therefore, this model can be used to predict the withdrawal capacity of M-T joint. 


\section{CONCLUSIONS}

In this study, the effects of tenon sizes, length and width, on withdrawal load capacity of M-T joint were studied numerically using FEM combining with response surface model. Following conclusions were drawn: (1) The tenon sizes have remarkable effect on withdrawal load capacity of M-T joint. (2) The effect of tenon length on withdrawal load capacity of M-T joint is greater than the one of tenon width. (3) It is recommended that the tenon length is greater than tenon width and smaller than twice tenon width in designing the tenon sizes of M-T joint especially subjected to withdrawal load. (4) The method of combining FEM and response surface method is an efficient way to optimize the tenon sizes, which can help researchers and engineers, know more about the details of wood structures visually and reduce the costs of time and materials used to conduct experiments.

Further studies can focus on numerically and experimentally optimizing the tenon sizes of M-T joint considering the tenon length, tenon width and tenon thickness together when subjected to bending and withdrawal loads.

\section{ACKNOWLEDGMENTS}

This work was supported by a Scientific Research Foundation of Wuyi University for Doctor (BSQD1901), Scientific Research Foundation of Metasequoia teacher (163104060) and Project from International Cooperation Joint Laboratory for Production, Education, Research and Application of Ecological Health Care on Home Furnishing.

\section{REFERENCES}

1. Chen Y.S., Zhu J., 2019: Study on bending characteristics of fast growing eucalyptus bookcase shelves by using Burgers model. Wood Research 64(1): 137-144.

2. Çolakoglu, M.H., Apay, A.C., 2012: Finite element analysis of wooden chair strength in free drop. International Journal of Physical Sciences 7(7): 1105-1114.

3. Derikvand, M., Smardzewski, J., Ebrahimi, G., Dalvand, M., Maleki, S., 2013: Withdrawal force capacity of mortise and loose tenon T-type furniture joints. Turkish Journal of Agriculture and Forestry 37: 377-384.

4. Diler, H., Acar, M., Balıkçı, E., Demirci, S., Erdil, Y.Z., 2017: Withdrawal force resistance of T-type furniture joints constructed from various heat-treated wood species. BioResources12(4): 7466-7478.

5. Džinčić, I., Nestorović, B., Dacić, V., 2016: The effect of shoulder on the strength of the oval tenon-mortis. Glasnik Sumarskog fakulteta 113: 35-46.

6. Eckelman, C.A., Haviarova, E., 2006: Effect of shoulders on bending moment capacity of round mortise and tenon joints. Forest Products Journal 56: 82-86.

7. Eckelman, C.A., Haviarova, E., Tankut, A., Denizli, N., Akcay, H., Erdil, Y., 2004: Withdrawal capacity of pinned and unpinned round mortise and tenon furniture joints. Forest Products Journal 54(12): 185-191.

8. Erdil, Y.Z., Kasal, A., Eckelman, C.A., 2005: Bending moment capacity of rectangular mortise and tenon furniture joints. Forest Products Journal 55(12): 209-213.

9. Hu, W.G., Guan, H.Y., 2017a: Study on elastic constants of beech in different stress states. Journal of Forestry Engineering 2(6): 31-36. 
10. Hu, W.G., Guan, H.Y., 2017b: Investigation on withdrawl force of mortise and tenon joint based on friction properties. Journal of Forestry Engineering 2(4): 158-162.

11. Hu, W.G., Guan, H.Y., 2019: A finite element model of semi-rigid mortise-and-tenon joint considering glue line and friction coefficient. Journal of Wood Science 65: 14.

12. Hu, W.G., Wan, H., Guan, H.Y., 2019: Size effect on the elastic mechanical properties of beech and its application in finite element analysis of wood structures. Forests 10(9): 783,13 pp.

13. Kasal, A., Smardzewski, J., Kuşkun, T., Erdil, Y.Z., 2016: Numerical analyses of various sizes of mortise and tenon furniture joints. BioResources 11: 6836-6853.

14. Kilic, K., Kasal, A., Kuskun, T., Acar, M., Edil, Y.Z., 2018: Effect of tenon size on static front to back loading performance of wooden chairs in comparison with acceptable design loads. BioResources 13(1): 256-271.

15. Likos, E., Haviarova, E., Eckelman, C.A., Erdil, Y.Z., Özcifci, A., 2012: Effect of tenon geometry, grain orientation, and shoulder on bending moment capacity and moment rotation characteristics of mortise and tenon joints. Wood and Fiber Science 44(4): 462-469.

16. Liu, J.X., Zhou, W., Li, C., 2018: Stress wave vibration characterization of cross section of $\log$ using finite element method. Journal of Forestry Engineering 3(6): 19-24.

17. Oktaee, J., Ebrahimi G., Layeghi, M., Ghofrani, M., Eckelman C.A., 2014: Bending moment capacity of simple and haunched mortise and tenon furniture joints under tension and compression loads. Turkish Journal of Agriculture and Forestry 38(2): 291-297.

18. Renbutsu, T., Koizumi, A., 2018: Withdrawal properties of glued, round, mortise and tenon joints using greenwood shrinkage as a clamping pressure. Mokuzai Gakkaishi 64(5): 187-194.

19. Silvana, P., Smardzewski, J., 2010: Effect of glue line shape on strength of mortise and tenon joint. Drvna Industrija 61(4): 223-228.

20. Smardzewski, J., 2008: Effect of wood species and glue type on contact stresses in a mortise and tenon joint. ARCHIVE Proceedings of the Institution of Mechanical Engineers Part C Journal of Mechanical Engineering Science 222(12): 2293-2299.

21. Wilczyński, A., Warmbier, K., 2003: Effect of joint dimensions on strength and stiffness of tenon joints. Folia Forestalia Polonica 34: 53-66.

22. Xi, X., Yang, Y., Zhang, Z.F., 2020: Pull-out force and finite element analysis of T-type components of Vitex negundo L. scrimber with different node forms. Journal of Forestry Engineering 5(1): 182-187.

23. Záborský, V., Borůvka, V., Kašičková, V., Ruman, D., 2017: Effect of wood species, adhesive type and annual ring directions on the stiffness of rail to leg mortise and tenon furniture joints. BioResources 12: 7016-7031.

24. Zhao, Z., Sakai, S., Wu, D., Chen, Z., Zhu, N., Huang, C., Sun, S., Zhang, M., Umemura, K., Yong, Q. 2019: Further exploration of sucrose-citric acid adhesive: investigation of optimal hot-pressing conditions for plywood and curing behavior. Polymers 11: 1996.

25. Zhou, C.M., Yu, M.N., Zhou, T., 2018: Experimental study on three-dimensional shape mapping of complex furniture. EURASIP Journal on Image and Video Processing 9: 89.

26. Chen, Y.,Yang, Y., Zhang, Z., 2019: Study on small-diameter wood scrimber and furniture design. Journal of Forestry Engineering 4(1): 155-159. 
TiAnXING ZHANG

WuYi UNIVERSITY

School of Art and Design

JIANGMEN 529020

ChINA

Wengang Hu*

Nanjing Forestry University

Co-Innovation Center of Efficient Processing and Utilization of Forest

Resources,

College of Furnishings and Industrial Design

NANJING 210037

China

*Corresponding author: hwg@njfu.edu.cn 